\title{
Radiometric Analysis of Canal and Body of Lumbar Vertebrae among Population of Central Nepal
}

\author{
Dil Islam Mansur, ${ }^{1}$ Subindra Karki, ${ }^{2}$ Dilip Kumar Mehta, ${ }_{1}^{1}$ Pragya Shrestha, ${ }^{1}$ Sunima Maskey, ${ }^{1}$ Sheprala \\ Shrestha ${ }^{1}$ \\ ${ }^{1}$ Department of Anatomy, Kathmandu University School of Medical Sciences, Dhulikhel, Nepal, ${ }^{2}$ Department of \\ Radio-diagnosis, Dhulikhel Hospital/Kathmandu University Hospital, Dhulikhel, Nepal.
}

\begin{abstract}
Background: Lumbar region is the most vulnerable area for the common symptom of backache. The lumbar part of spinal canal encloses the cauda equina. Narrowing of the canal can be either developmental or acquired. This leads to compression of the cauda equina and subsequently pain develops which may be further associated with neurological features. The aim of the present study was to measure the dimensions of lumbar vertebrae.
\end{abstract}

\begin{abstract}
Methods: The present study was a descriptive and cross-sectional type. It consisted of 266 images of computed tomography scan of individuals. The various dimensions of lumbar vertebral canal and body were measured in millimeter. The descriptive statistical analysis was done.

Results: The mean of the transverse diameter of lumbar vertebral canal increased from L1 to L5 but the antero-posterior diameter decreased from L1 to L4 followed by increased at L5. It was also observed that both transverse and antero-posterior diameter of body progressively increased from L1 to L5 vertebrae. The canal-body ratio was inconsistent for lumbar vertebrae. There were significant differences in various dimensions of lumbar vertebrae between males and females.
\end{abstract}

Conclusions: The anatomical knowledge of the dimensions of canal and body of lumbar vertebral may be helpful for the clinicians during radiological interpretations and surgical procedures of lumbar spine pathology.

Keywords: back pain; lumbar vertebrae; stenosis.

\section{INTRODUCTION}

The vertebral column is the central bony pillar of the body. ${ }^{1}$ It is a curved linkage of individual bone or vertebra. Each vertebra has a vertebral foramen. A continuous series of vertebral foramina runs through the articulated vertebrae posterior to their bodies and anterior to vertebral arch. Collectively constitutes the vertebral canal. It transmits and protects the spinal cord, nerve roots, their coverings and vasculature. ${ }^{2}$ It protects the spinal cord and also supports the weight of the head, upper limbs and the trunk, which it transmits to the lower limbs. ${ }^{1}$ Lumbar spinal stenosis is the narrowing of lumbar spinal canal which may compress the spinal cord and nerves at the level of the lumbar vertebra. ${ }^{3}$ It may cause low back pain, pain or abnormal sensations in the lower limbs or loss of bladder and bowel control. ${ }^{4}$

Low back pain is one of the common health problems affecting up to $85 \%$ of people at least once in their lifetime. ${ }^{5}$ The measurement of dimensions of lumbar canal and body has become an important tool for diagnosis and treatment of spinal stenosis. ${ }^{6-8}$ Currently, the Canal and Body ratio is also taken as index for calculating the degree of spinal stenosis. ${ }^{9}$ The aim of the present study was to establish a baseline data for lumbar spinal canal and body which may help clinicians for diagnosis and plan for proper treatment of lumbar spinal stenosis.

\section{METHODS}

A descriptive cross sectional study was conducted at Kathmandu University School of Medical Sciences, Dhulikhel during the period from February to March, 2020. A total of 266 Computed Tomography (CT) images of adult individuals (142 males and 124 females) were collected from Department of Radio-diagnosis. Ethical approval was received from Institutional Review Committee (Ref. no. 03/20). The images of individual with normal spinal architecture were included and those having history of spinal surgery, deformities and pre-existing spinal pathology was excluded for the study. Various dimensions of vertebral canal and body of all

Correspondence: Dr. Dil Islam Mansur, Department of Anatomy, Kathmandu University School of Medical Sciences, Dhulikhel, Nepal. Email: dilislam@kusms.edu.np. Phone: +977-9861484747. Article received: 2020-03-28. Article accepted: 2020-05-26. 
Mansur et al. Radiometric Analysis of Canal and Body of Lumbar Vertebrae among..

lumbar vertebrae was measured in axial and sagittal sections by lines drawn on the CT scan images and the values were directly recorded from the monitor screen in millimeter. Transverse diameter (TD) of vertebral canal was measured as the distance between the medial surface of the right and left pedicles (Figure 1). ${ }^{10}$ Antero-posterior diameter (APD) of vertebral canal was measured as the distance from posterior margin of vertebral body to anterior margin of junction of two laminae (Figure $2)^{11}$ Transverse diameter (TD) of vertebral body was measured at the distance between lateral margins vertebral body (Figure 3). ${ }^{10}$ Antero-posterior diameter (APD) of vertebral body was measured from midpoint of anterior to posterior margins of vertebral body (Figure 4). ${ }^{11}$ The canal-body ratio (CBR) was calculated by dividing TD of spinal canal by TD of vertebral body. ${ }^{12}$ The observed data was entered in Microsoft Office Excel 2013 and data was analyzed by using SPSS version 20.0.

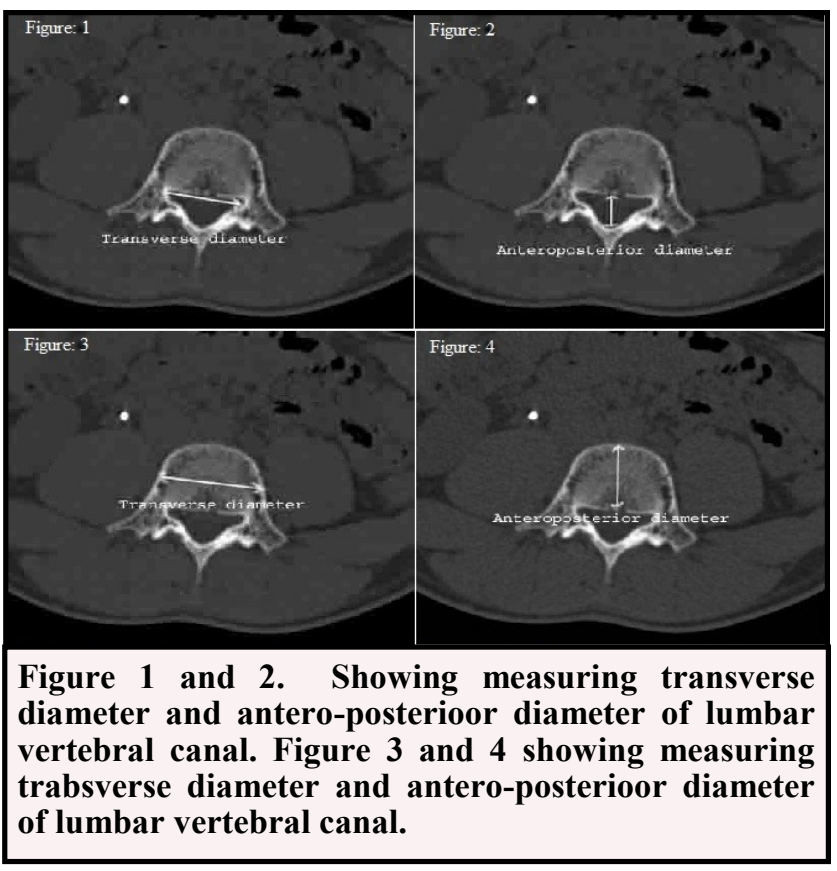

RESULTS

It was found that the transverse diameter of the vertebral canal showed a gradually increased from $\mathrm{L} 1$ to L5. It was minimum at L1 and maximum at L5 (Table 1 and 2). The differences between the mean transverse diameters in males and females at all the five lumbar vertebral levels were found to be highly significant $(p<0.05)$ except at L4 (Table 2$)$. Antero-posterior diameter of vertebral canal showed a gradual decreased from L1 to L4 followed by increased at L5 (Table 1). Similar pattern was seen among females (Table 2). This decreased pattern was observed from L1 to L3 followed by increased from L4 to L5 vertebral level among males. The present study showed the progressive increase in transverse diameter of vertebral body from L1 to L5 vertebrae (Table 1). The same trend was observed in both genders. It was also found that the mean values were found to be higher in males than females at all level of vertebrae with statistically significant $(\mathrm{p}<0.005)$ differences (Table 2$)$. A gradual increase in antero-posterior diameter of vertebral body was found from L1 to L5 vertebrae (Table 1) which was also observed in both genders. In males, the mean values were noticed to be significantly higher $(p<0.05)$ than females at all level of vertebrae (Table 2). It was also observed that the canal-body ratio was not found constant at any vertebral level in both sexes (Table 1 and Table 2).

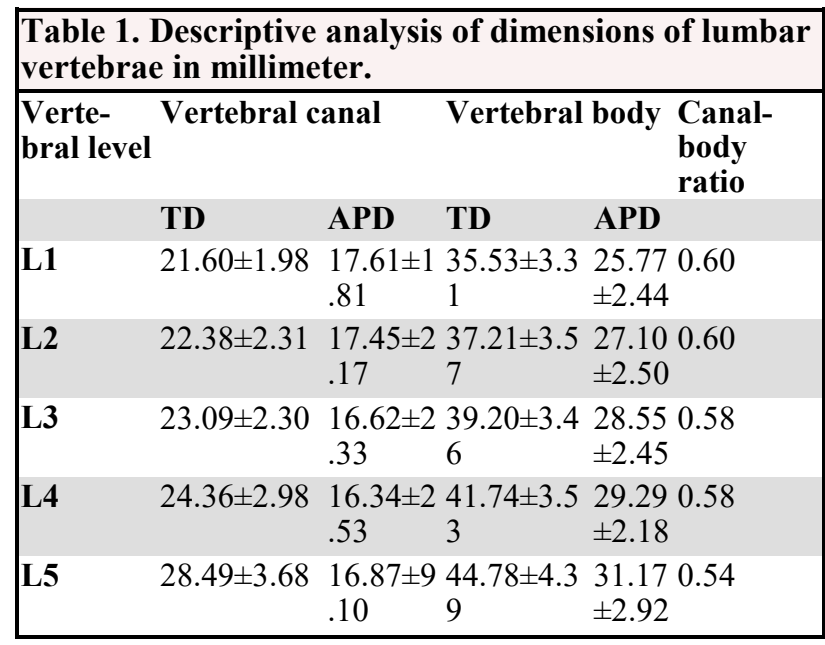

Table 2. Descriptive analysis of dimensions of lumbar vertebrae of both genders in millimeter.

\begin{tabular}{|c|c|c|c|c|c|c|}
\hline \multirow{3}{*}{\multicolumn{2}{|c|}{$\begin{array}{l}\text { Vertebral level } \\
\text { Ver- TD Males } \\
\text { tebra }\end{array}$}} & L1 & $\overline{\mathrm{L} 2}$ & $\mathbf{L 3}$ & L4 & $\overline{L 5}$ \\
\hline & & $22.01 \pm 1$ & $22.86 \pm$ & $23.52 \pm$ & $24.72 \pm$ & \multirow[t]{2}{*}{$29.19 \pm 3.94$} \\
\hline & & .92 & 2.28 & \multirow{2}{*}{$\begin{array}{l}2.31 \\
2260 \pm\end{array}$} & \multirow{2}{*}{2.61} & \\
\hline \multirow{3}{*}{$\begin{array}{l}\text { l } \\
\text { Ca- } \\
\text { nal }\end{array}$} & & $21.62 \pm 2$ & $21.84 \pm$ & & & \multirow[t]{2}{*}{$27.69 \pm 3.19$} \\
\hline & & .12 & 2.22 & 2.19 & 3.32 & \\
\hline & $\mathrm{p}$-value & $<0.001$ & $<0.001$ & 0.01 & 0.38 & 0.01 \\
\hline \multirow{5}{*}{$\begin{array}{l}\text { AP } \\
\mathbf{D}\end{array}$} & \multirow[t]{2}{*}{ Males } & $17.72 \pm 1$ & $17.37 \pm$ & \multirow{2}{*}{$\begin{array}{l}16.30 \pm \\
2.23\end{array}$} & \multirow{2}{*}{$\begin{array}{l}16.32 \pm \\
2.37\end{array}$} & \multirow{2}{*}{$16.40 \pm 2.84$} \\
\hline & & .56 & 2.17 & & & \\
\hline & \multirow[t]{2}{*}{ Females } & $17.73 \pm 2$ & $17.30 \pm$ & $16.62 \pm$ & $16.21 \pm$ & \multirow{2}{*}{$16.43 \pm 2.35$} \\
\hline & & .02 & 2.03 & 2.38 & 2.3 & \\
\hline & p-value & 0.89 & 0.21 & 0.02 & 0.3 & 0.93 \\
\hline \multirow{5}{*}{$\begin{array}{l}\text { Ver- TD } \\
\text { tebra } \\
\text { l } \\
\text { Body }\end{array}$} & \multirow[t]{2}{*}{ Males } & $37.23 \pm 3$ & $39.03 \pm$ & \multirow{2}{*}{$\begin{array}{l}41.00 \pm \\
3.15\end{array}$} & \multirow{2}{*}{$\begin{array}{l}43.60 \pm \\
3.13\end{array}$} & \multirow{2}{*}{$46.90 \pm 3.95$} \\
\hline & & .15 & 3.40 & & & \\
\hline & \multirow[t]{2}{*}{ Females } & $33.55 \pm 2$ & $35.10 \pm$ & $37.11 \pm$ & $39.57 \pm$ & \multirow{2}{*}{$42.31 \pm 3.50$} \\
\hline & & .21 & 2.43 & 2.51 & 2.65 & \\
\hline & p-value & $<0.001$ & $<0.001$ & $<0.001$ & $<0.001$ & $<0.001$ \\
\hline \multirow{5}{*}{$\begin{array}{l}\text { AP } \\
\text { D }\end{array}$} & \multirow[t]{2}{*}{ Males } & $26.72 \pm 2$ & $28.23 \pm$ & \multirow{2}{*}{$\begin{array}{l}29.60 \pm \\
2.37\end{array}$} & \multirow{2}{*}{$\begin{array}{l}30.20 \pm \\
2.20\end{array}$} & \multirow[t]{2}{*}{$32.39 \pm 2.84$} \\
\hline & & .40 & 2.39 & & & \\
\hline & \multirow[t]{2}{*}{ Females } & $24.67 \pm 2$ & $25.78 \pm$ & \multirow{2}{*}{$\begin{array}{l}27.33 \pm \\
1.95\end{array}$} & \multirow{2}{*}{$\begin{array}{l}28.23 \pm \\
1.62\end{array}$} & \multirow{2}{*}{$29.76 \pm 2.32$} \\
\hline & & .01 & 1.93 & & & \\
\hline & p-value & $<0.001$ & $<0.001$ & $<0.001$ & $<0.001$ & $<0.001$ \\
\hline \multirow{2}{*}{$\begin{array}{l}\text { Canal- } \\
\text { body } \\
\text { ratio }\end{array}$} & Males & 0.59 & 0.58 & 0.57 & 0.57 & 0.62 \\
\hline & \multicolumn{2}{|c|}{ Females 0.64} & 0.62 & 0.61 & 0.6 & 0.65 \\
\hline
\end{tabular}

\section{DISCUSSION}

Vertebral column morphology is influenced by various factors such as environmental and mechanical factors of our everyday lifestyle and internally by hormonal, genetic and metabolic 
factors. These all affect its ability of everyday life to react to the dynamic forces which are much influenced by occupation, locomotion and posture. ${ }^{2}$ It is made to act as shock absorber, lower down the impact and longitudinal stiffness and help in proper muscular function. The alteration of this normalcy in curve has been noticed to be associated with sciatica and low back pain. ${ }^{13}$

The assessment of the size of the vertebral canal is an important diagnostic procedure for low back pain of unknown etiology. Any pathological changes in the diameter of the vertebral canal might be associated with low back pain. ${ }^{14}$ Size of the canal diameter is one among several factors responsible for lumbar spinal spondiolysis. ${ }^{15}$ It is one of the most common reason for spinal surgical interventions nowadays but still radiological data defining set measurement points to quantify stenosis are limited. ${ }^{16}$

A cranio-caudal increased in the mean transverse diameter of vertebral canal values from L1 to L5 was recorded in the present study. The similar trend was also recorded by a study conducted in western part of Nepal. ${ }^{15}$ The finding of this study is also supported by studies conducted in Gujarati, Indian ${ }^{17}$ and Egyptian population. ${ }^{18}$ However, the finding of the present study is in contrary to the finding of Zindrick et al., who have reported a decreasing transverse diameter of lumbar vertebral canal from L1 to L5. ${ }^{19}$ On the other hand, Speciale et al found that the transverse diameter was constant at L1 and L2 and then increased gradually till L5 vertebra. ${ }^{20}$ This variation may be due to it being the tendency for greater diameters at L4 and L5 level which is an adaptation to accommodate sacral nerve roots during angular movements of the vertebral column.

The transverse diameter of lumbar vertebral canal was found higher in males than females at all level of vertebrae. Eisenstein found that the mean values of transverse diameter of lumbar vertebral canal were found higher in males than females at all level of vertebrae with statistically significant differences $^{21}$ which are accordance with the findings of this study. Interestingly, Sethi et al., mentioned mean values for transverse diameter were higher in females than males at all level of vertebrae with statistically significant differences. ${ }^{16}$ However, a study showed no significant differences between males and females. ${ }^{14}$ This difference may be due to the greater differences in general somatic size of the body of males as compare to females.

There was a discrepancy in the literature regarding antero-posterior diameter of lumbar vertebral canal. The mean antero-posterior diameter showed gradual decreased from L1 to L4 vertebral level then increased at L5 level in the present study. In contrast, some studies depicted a cranio-caudal decreased in the antero-posterior diameter from L1 to L5. ${ }^{15,22}$ Moreover there are few data in the previous studies which showed a cranio-caudal increased in antero-posterior diameter. ${ }^{23,24} \mathrm{~A}$ study revealed that the mean values for antero-posterior diameter decreased from L1 to L3, then increased from L3 to L5, making L3 the narrowest lumbar segment in the sagittal plane. ${ }^{25}$ A study also observed antero-posterior diameter increased from L1-L2 and reduction in the diameter occurred at level L3. It again showed increase from L4-L5. ${ }^{26} \mathrm{It}$ was also observed that the mean values for anteroposterior diameter of vertebral canal were found to be higher in males than females at L2 and L4 vertebral levels whereas these values were found to be higher among females at L1, L3 and L5 vertebral levels. Contrary to this study, Zhou et al and Alam et al., suggested that the antero-posterior diameter was higher among males than females at all levels of vertebrae. ${ }^{24,27}$ A study done in India in the people of Telangana quoted the values to be higher among females than males. ${ }^{28}$ The differences between male and female are found to be insignificant as compared to earlier research work in South Indian population. ${ }^{29}$ These variations may be due to genetic and environmental factors.

The present study showed the gradual increment in mean vertebral body transverse diameter from L1 to L5 which was similar to the result noted by a study done in western region of Nepal. ${ }^{15}$ Abbas et al., also got the same pattern in lower three lumbar vertebrae. ${ }^{23}$ Cranio-caudal increase in transverse vertebral diameter is ascribed by increasing weight of the body. On the other hand, Tan et al got the lower value of mean vertebral body transverse diameter at L5 than L4. ${ }^{30}$ Variation in vertebral morphometry is common in different parts of the world due to racial and ethnic variations.

The studies have quoted that the transverse diameter of vertebral body followed an increasing trend from L1 to L5 vertebrae ${ }^{31,32}$ which are accordance with this study. The North Indian males have higher values of transverse diameter of vertebra in comparison to females ${ }^{32}$ which is agreement with this study. This study showed the higher mean vertebral body transverse diameter among males than females with gradual increment from L1 to L5 which is agreement with the result obtained by Alam et al. ${ }^{27}$ Growth hormone and sex steroids may be responsible factors for sexual dimorphism. The wider male's vertebra is necessary to support larger male's skeleton. Only females showed the similar result in the studies of Rakhawy et al., and Zhou et al., who found the gradual increased mean vertebral body transverse diameter in lower three lumbar vertebrae. ${ }^{14,24}$ The transverse diameter of vertebral body increases 
cranio-caudally suggesting gradual increased in size of the vertebral column due to its weight bearing actions.

The present study showed that there was gradual increment in the mean vertebral body anteroposterior diameter from L1 to L5 being minimum at $\mathrm{L} 1$ and maximum at L5. The similar pattern was found by Abbas et al in the lower three lumbar vertebrae. ${ }^{23}$ In contrast Tan et al found the gradual increment of vertebral body antero-posterior diameter from L1 to L3 and decreased at L4 and it was maximum at L5. ${ }^{30}$ This suggesting environmental and ethnic factors as source of geographical differences.

The mean vertebral body antero-posterior diameter showed gradual increment from L1 to L5 in both sex in the present study. The similar pattern was found only in the females by Alam et al., ${ }^{27}$ and Amonoo-kuofi. ${ }^{33}$ Zhou et al., also found the similar result in both sex in lower three lumbar vertebrae in their study. ${ }^{25}$ In contrast, Alam et al., and Amonoo-kuofi found the less mean vertebral body antero-posterior diameter at L5 than L4. ${ }^{27,33}$ The increase in size of lower lumbar vertebrae is endorsed to it being the area for various movements and the maximum load bearing.

Variations can occur in relation to general somatic size within a population but transverse diameter of the spinal canal of any lumbar vertebra is proportional to the size of the vertebral body at that

\section{REFERENCES}

1. Snell S. Richard. Clinical anatomy By Regions, $9^{\text {th }}$ edition. Wolters Kluwer: Lippincott Williams and Wilkin 2012:683-719.

2. Standring S. Gray's Anatomy the anatomical basis of clinical practice, $40^{\text {th }}$ edition. In: Chap The Back. Churchill-Livingstone: Elsevier 2008:712-23.

3. Vogt MT, Cawthon PM, Kang JD, Donaldson WF, Cauley JA, Nevitt MC. Prevalence of symptoms of cervical and lumbar stenosis among participants in the osteoporotic fractures in men study. Spine. 2006;31(13):1445-51.

4. Hicks GE, Gaines JM, Shardell M, Simonsick EM. Associations of back and leg pain with health status and functional capacity of older adults: findings from the retirement community back pain study. Arthritis Rheum. 2008;59 (9):1306-13.

5. Anderson DJ, Adcock DF, Chovil AC, Farrell JJ. Ultrasound lumbar canal measurement in hospital employees with back pain. Brit J Industrial Med. 1988;45:552-5.

6. Schonstrom NS, Bolender N, Spengler DM. The pathomorphology of spinal stenosis as seen on CT scans of the lumbar spine. Spine. 1985;10:806-11. level. ${ }^{34}$ The size of vertebral body should vary proportionately with the build of an individual. Calculation of canal-body ratio for different segments helps in specifying whether an individual's measurement on spinal canal are within normal limits for the respective vertebral body size or not, thus helping to identify spinal canal stenosis. ${ }^{33}$ In a study, Jadhav et al., observed that the canal-body ratio was not constant at any vertebral level in both sexes ${ }^{9}$ which are quite similar to the present study. In contrast, Nirvan et al., got the constant canal-body ratio at all lumbar vertebral levels in both sexes. ${ }^{17}$ It may be due to the fact that there are ethnic as well as racial variations in the size of lumbar vertebrae.

\section{CONCLUSIONS}

The mean values for the transverse diameters of the vertebral canal were increased from L1 to L5 whereas the antero-posterior diameters were decreased gradually from L1 to L4 followed by increased at L5. A gradual increment in the transverse and the antero-posterior diameter of vertebral body were observed from L1 to L5 vertebrae in both sexes. The canal-body ratio was not found constant at any vertebral level in both sexes. This anatomical knowledge of the dimensions of lumbar vertebral canal and body may be helpful for the clinicians in the diagnosis and making plan for treatment of lumbar spine pathology. It could also generate a baseline data for Nepalese population which can be assisted in the further research activities.

7. Christenson PB. The radiologic study of the normal spine. Radiol Clin North Am. 1977;15 (2):133-54.

8. Hamanashi C, Matukura N, Fujita M, Tomihara $\mathrm{M}$, Tanaka S. Cross-sectional area of the stenotic dural tube measured from the transverse views of magnetic resonance imaging. J Spinal Disord. 1994; 7:388-93.

9. Jadhav AS, Katti AS, Herekar NG. Transverse diameter of lumbar vertebrae in Western Maharashtra population. Int J Emerg Trends Sci Technol. 2011;1(3):130-7.

10. Mallik M, Paudel K, Subedi ND, Sah S, Subedee A, Adhikari D. A study of measurements of spinal canal at the level of lower three lumbar vertebra by 16 slice $\mathrm{CT}$ scanner in Nepalese population. JCMS Nepal. 2014;10(4):6-11.

11. Fetouch FA. Age and gender related changes in midsagittal dimensions of the lumbar spine in normal Egyptians: MRI study. Int J Cur Res Rev. 2015;7(2):21-40

12. Jadhav AS, Katti AS, Herekar NG, Jadhav SB. Osteological study of lumbar vertebrae in Western Maharashtra population. J Anat Soc India. 2013;62:10-6.

13. Kim HJ, Lee HM, Kim HS, Moon ES, Park $\mathrm{JO}$, Lee KJ, et al. Life expectancy after lumbar 
spine surgery: one- to eleven-year follow-up of 1015 patients. Spine. 2008;33(19):2116-21.

14. Rakhawy ME, Rahman AE, Shahat A, Labib I, Abdulaziz E. Lumbar vertebral canal stenosis: concept of morphometric and radiometric study of the human lumbar vertebral canal. Turkish Society of Anatomy and Clinical Anatomy. 2010:51-62.

15. Shrestha B, Dhungana S. Measurement of transverse and sagittal diameter of the lumbar vertebral canal in people from Western region of Nepal. Int J Infect Microbiol. 2013;2(2):55-8.

16. Sethi R, Singh V, Chauhan BKS, Thukral BB. A study of transverse diameter of lumbar vertebral canal in north Indian population. Int J Anat Res. 2015;3(3):1371-5.

17. Nirvan AB, Pensi CA, Patel JP, Shah GV, Dave RV. A study of inter-pedicular distances of the lumbar vertebrae measured in plain anteroposterior radiograph in Gujaratis. J Anat Soc India. 2005;54(2):1-9.

18. Tarek A, Osama A. Geometrical dimensions and morphological study of the lumbar spinal canal in the normal Egyptian population. Orthopedics. 2013;36(2):229-34.

19. Zindrick MR, Wiltse LL, Widell HE. A biomechanical study of intrapedicular screw fixation in the lumbosacral spine. Clin Orthop Relat Res. 1986;203:99-112.

20. Speciale AC, Pietrobon R, Urban CW, Richardson WJ, Helms CA, Major N, et at. Observer variability in assessing lumbar spinal stenosis severity on magnetic resonance imaging and its relation to cross-sectional spinal canal area. Spine. 2002;27(10):1082-6.

21. Eisenstein S. The morphometry and pathological anatomy of the lumbar spine in South African negroes and caucasoids with spe-cific reference to spinal stenosis. J Bone Joint Surg Br. 1977;59 (2):173-80.

22. Ahmad T, Goel P, Ramesh Babu CS. A study of lumbar canal by MRI in clinically symptomatic and asymptomatic subjects. J Anat Soc India. 2011;60(2):184-7.

23. Abbas J, Hamoud K, May H, Hay O, Medlej B, Masharawi Y, et al. Degenerative lumbar spinal stenosis and lumbar spine configuration. Eur Spine J. 2010;19(11):1865-73.
24. Zhou SH, McCarthy ID, McGregor AH, Coombs RRH, Hughes SPF. Geometrical dimensions of the lower lumbar vertebraeanalysis of data from digitised CT images. Eur Spine J. 2000;9(3):242-8

25. Panjabi MM, Goel V, Oxland T, Takata K, Duranceau J, Krag M, et al. Human lumbar vertebrae: quantitative three-dimensional anatomy. Spine. 1992;17(3):299-306.

26. Banik S, Rajkumari A. Morphometric analysis of lumbar vertebrae and its applied clinical importance. Int J Anat Res. 2019;7(2.1):6381-6.

27. Alam MM, Waqas M, Shallwani H, Javed G. Lumbar morphometry: A study of lumbar vertebrae from a Pakistani population using computed tomography scans. Asian Spine J. 2014;8(4):421-6.

28. Kumar AP, Kasturi A, Ramu C, Nadadur S. Morphometric analysis of lumbar vertebrae in tertiary care institutions in Telangana. Annals of International Medical and Dental Research. 2016;2(1):157-62.

29. Vinay KV, Vishal K. A study of transverse diameter of the lumbar spinal canal in normal south indians using CR-35X digitizer. Indian Journal of Fundamental and Applied Life Sciences. 2012;2(2):30-5

30. Tan SH, Teo EC, Chua HC. Quantitative threedimensional anatomy of lumbar vertebrae in Singaporean Asians. Eur Spine J. 2002;11:1528.

31. Chhabra S, Gopinathan K, Chhibber SR. Transverse diameter of the lumbar vertebral canal in North Indians. J Anat Soc India. 1991;40(1):25-32.

32. Bhaumik M, Bhaumik U. A morphometric study of canal-body ratio of the lumbar vertebrae in western region of Rajasthan through anteroposterior radiographs. International Journal of Research and Review. 2019;6(7):28-33.

33. Amonoo-kuofi HS. The sagittal diameter of the lumbar vertebral canal in normal adult Nigerians. J Anat. 1985;140(1):69-78.

34. Jones RA, Thomson JL. The narrow lumbar canal. A clinical and radiological review. J Bone Joint Surg Br. 1968;50(3):595-605.

Citation: Mansur DI, Karki S, Mehta DK, Shrestha P, Maskey S, Shrestha S. Radiometric Analysis of Canal and Body of Lumbar Vertebrae among Nepalese Population. JCMS Nepal. 2020; 16(2):57-61. 